\title{
Article \\ Work-Related Challenges among Primary Health Centers Workers during COVID-19 in Saudi Arabia
}

\author{
Khalid Al-Mansour 1,2,*, Abdullatif Alfuzan ${ }^{1}$, Danya Alsarheed ${ }^{2}$, Munwer Alenezi ${ }^{2}$ and Fouad Abogazalah $^{2}$ \\ 1 Department of Social Studies, College of Arts, King Saud University, Riyadh 11451, Saudi Arabia; \\ Aalfuzan1@ksu.edu.sa \\ 2 General Administration for Primary Health Centers, Ministry of Health, Riyadh 12628, Saudi Arabia; \\ Dalsarheed@moh.gov.sa (D.A.); Malonezy@moh.gov.sa (M.A.); Fabogazalah@moh.gov.sa (F.A.) \\ * Correspondence: Kalmansour1@ksu.edu.sa; Tel.: +966-54-855-2528
}

Citation: Al-Mansour, K.; Alfuzan, A.; Alsarheed, D.; Alenezi, M.; Abogazalah, F. Work-Related Challenges among Primary Health Centers Workers during COVID-19 in Saudi Arabia. Int. J. Environ. Res. Public Health 2021, 18, 1898. https:// doi.org/10.3390/ijerph18041898

Academic Editor: Byoung-Hee Lee Received: 16 December 2020

Accepted: 10 February 2021

Published: 16 February 2021

Publisher's Note: MDPI stays neutral with regard to jurisdictional claims in published maps and institutional affiliations.

Copyright: (c) 2021 by the authors. Licensee MDPI, Basel, Switzerland. This article is an open access article distributed under the terms and conditions of the Creative Commons Attribution (CC BY) license (https:// creativecommons.org/licenses/by/ $4.0 /)$.

\begin{abstract}
This study aimed to identify certain occupational risk factors for stress among healthcare workers (HCWs) during the COVID-19 pandemic. Using a multistage random sampling approach, an online questionnaire was applied to collect data on role conflict and ambiguity, self-esteem and social support from 1378 HCWs working in primary health centers (regular and fever clinics; clinics specialized in managing patients with COVID-19 symptoms) across Saudi Arabia. The results showed that stress correlated positively with role conflict and ambiguity and negatively with social support. HCWs in fever clinics exhibited significantly more stress and role conflict and ambiguity than those who were working in regular primary healthcare centers. In conclusion, role conflict and ambiguity and social support were determinants for stress among HCWs, especially those working in fever clinics.
\end{abstract}

Keywords: stress; role conflict; role ambiguity; social support; self-esteem; primary healthcare centers; COVID-19; Saudi Arabia

\section{Introduction}

Coronavirus Disease-2019 (COVID-19) is a disease caused by Severe Acute Respiratory Syndrome that was firstly detected in Wuhan, China in December 2019 [1]. By March 2020, the rapid increase of COVID-19 cases in many countries has reached pandemic proportions [2]. On 11 March 2020, the number of confirmed cases was 118,000, with over 4000 deaths [3]. The increase in the number of confirmed cases and deaths continued to reach nearly 50 million confirmed cases and more than 1,245,000 deaths by 8 November 2020 [4].

With regards to Saudi Arabia, the first case was officially reported on 2 March 2020 [5-7]. According to the Johns Hopkins Coronavirus Resource Center on November 8, 2020, the number of confirmed cases in Saudi Arabia exceeded 350,000, while the number of deaths was more than 5500 [8]. Therefore, Saudi Arabia has taken many precautionary measures during the pandemic to control the spread of the virus, such as imposing a lockdown, asking people to wear masks in public and launching online education $[7,9]$. In addition to providing free treatment to all citizens and residents, the country built up healthcare centers, named fever clinics, in all cities and governorates to receive only patients with COVID-19 symptoms [10]. All these efforts could be considered one of the reasons for increasing pressure on the health system, which may lead to a further increase in the level of stress among healthcare workers (HCWs).

Previous national and international studies, however, have shown high levels of stress among HCWs, whether in regular conditions or during the COVID-19 pandemic [6,11-15]. For example, the Middle East Respiratory Syndrome coronavirus (MERS-CoV) has been identified in 2012 in many countries worldwide and most cases were diagnosed in Saudi Arabia [16]. National and international studies by then documented increased stress among 
HCWs who dealt with MERS-CoV cases, especially those who were working in primary healthcare centers and this stress undermined their quality of healthcare [17-19].

In addition to sociodemographic characteristics, several work-related factors were suggested to affect the stress levels of HCWs, including role conflict and ambiguity, selfesteem and social support [20-24]. Role conflict and ambiguity can be attributed to the absence of clear and reliable data about the activities needed in a specific position, the unpredictability of performance results and information deficiency regarding the required tasks $[25,26]$. Self-esteem can be defined as positive or negative beliefs about oneself and it is also an important personal means to alleviate stress, while social support is seen as an individual's response to participating in social groups that help support one another [27-29]. Psychological stress theory can give us the important of both personal and environmental factors on stress level. Psychological stress theory is a theory that explain the stress and coping process and that theory was developed by Lazarus in his book Psychological Stress and the Coping Process in 1966 [30]. According to Lazarus and Folkman (1986) stress is defined as "a relationship with the environment that the person appraises as significant for his or her well-being and in which the demands tax or exceed available coping resources" [31]. The stress can result from two types of factors and these factors are personal and environmental factors [31]. General beliefs including self-esteem can be one of the personal factors that influence the appraisal among individuals [32]. According to Lambert and Lambert [33], self-esteem is one of the factors that might influence the level of stress among nurses. Different environmental factors might influence stress including constraints and resources [32]. Several studies found constraints such as work conflict and ambiguity can affect the level of stress among health care professionals as constraints [34,35]. Also, Social support as environmental resources can affect the level of stress among healthcare workers [36].

However, no study, to date, has investigated the environmental and personal impacts on the levels of stress among HCWs in Saudi Arabia during the COVID-19 pandemic. We also have no information on whether HCWs in fever clinics specialized to manage patients with COVID-19 symptoms experience the same stress levels and personal and environmental stressors as their counterparts in regular primary healthcare centers in Saudi Arabia. Thus, this research was conducted to identify the association between role conflict and ambiguity, self-esteem and social support with stress levels among HCWs in primary healthcare centers in Saudi Arabia. We also objected to assess the differences in stress, role conflict and ambiguity, self-esteem and social support between HCWs in regular healthcare centers and fever clinics.

\section{Materials and Methods}

This cross-sectional study was conducted on HCWs in the primary healthcare centers in Saudi Arabia using a multistage random sampling technique. Saudi Arabia is divided geographically into five regions; Central, Eastern, Western, Northern and Southern regions. The Saudi Minister of Health is represented in each region by the Directorates of Health Affairs $(n=20)$. Each directorate supervises regular primary healthcare centers $(n=2070)$ and fever clinics $(n=119)$. In this study, we randomly selected six regular health centers and two fever clinics from all directorates and sent emails to all workers in the selected centers and clinics, including electronic questionnaires, before sending reminders one week later. Data collection was started on 27 September 2020 and continued for three weeks. The anticipated time to complete the survey was approximately $10 \mathrm{~min}$. Based on power analysis with $\mathrm{G}^{*}$ Power software edition 3.1.9.7 for linear multiple regression analysis (with seven predictors, at least a medium effect of 0.10 and $95 \%$ power), the required sample size is between 235 and 245 .

\subsection{Participants}

Physicians, nurses, other health professionals (lab specialists, radiologists, pharmacists, social workers and epidemiologists) and other workers (administrators, receptionists 
and managers) who worked in the primary healthcare centers were the target population. All employees working (medical and non-medical jobs) in each randomly selected center were invited to participate in the study by using the official emails from the Ministry of Health. The total number of invited persons was 2007, of whom 1378 replied, representing a response rate of $69 \%$. The head of the primary healthcare center in each Health Affairs Directorate coordinated the data collection process in each health directorate. The principal author was available to contact when having any questions or facing any difficulties. The head of the primary healthcare center in each directorate of health affairs emailed the self-administrated survey link to the targeted participants. During the time frame of data collection, a weekly reminder was mailed to the targeted participants.

\subsection{Study Variables}

This study had one dependent variable (perceived stress) and several independent variables (role conflict and ambiguity, self-esteem and social support). Other covariates included age, gender, smoking, marital status, nationality, educational level, the type and the site of the healthcare center (regions) and job.

\subsection{Measures}

\subsubsection{Stress}

The Perceived Stress Scale (PSS) was used to measure stress in this study. The PSS has been vastly utilized as a measure of stress estimate with strong psychometric properties [37]. It includes ten items to appraise an individual's stress. The participants evaluated the degree to which life stressors were overpowering and unmanageable over the preceding month, on a scale ranging from 0 (never) to 4 (very often) and a higher score refers to a higher level of stress [37]. According to Cohen et al. [38], PSS has good validity since it is highly correlated with different scales such as self-reported health and health services measures, health behavior measures, smoking status and help-seeking behavior. Furthermore, research shows excellent validity and reliability with healthcare professionals in Saudi Arabia [39-41]. The scale in the current study has good reliability and validity (Cronbach's alpha 0.85). According to Chaaya et al., the Arabic version of the Perceived Stress Scale is valid [42].

\subsubsection{Self-Esteem}

Self-esteem is defined by Rosenberg [43] as a positive or negative attitude toward the self. The current study used the Rosenberg Self-Esteem Scale (RSES), which has been used significantly. The scale consists of 10 items as self-report and assessed participants based on a 4-point Likert scale varying from 1 (strongly disagree) to 4 (strongly agree) [44]. A higher score on the scale means higher self-esteem. Several studies have evaluated the reliability and validity of the RSES and found that the scale has acceptable reliability and validity $[45,46]$. In this study, Cronbach's alpha coefficients for this scale equaled 0.72 . Also, the scale has a good criterion validity since it has a significant relationship with the Perceived Stress Scale $(r=0.142, p<0.01)$.

\subsubsection{Social Support}

Social support is explained as "understood or real instrumental and/or meaningful provisions supplied by the group of society, social networks and confiding" [47]. The Multidimensional Scale of Perceived Social Support (MSPSS), which was used in this study, identifies perceptions of support from three vital dimensions of individuals' emotional support: family, friends and significant others. The MSPSS is composed of 12 self-administered items [48]. Responses choices are in the form of a 7-point Likert scale ranging from 1 (very strongly disagree) to 7 (very strongly agree) with a higher score on the scale reflecting higher social support. The MSPSS is validated for internal consistency and is acceptable for reliability [46,49-51]. Our study showed that it had good reliability (Cronbach's alpha $0.92)$. In addition, the scale is valid based on criterion validity $(r=-0.220, p<0.01)$. 


\subsubsection{Work Role Conflict}

Role conflict is defined as the concurrent event of at least two job pressures so that the consistency with one makes it very hard to respond to the next [52]. Bowling et al. (2017) developed a role conflict measure for workers, which was used in this study to assess work-role conflict among primary healthcare workers. It includes six measured items and the participants can respond to the questions on a 7-point Likert scale ranging from 1 (strongly disagree) to 7 (strongly agree) with a higher score on the scale pointing to a higher level of conflict. There is ample reliability and validity evidence depend on [53]. In the present study, the scale has a reliability (Chronbach's Alpha $=0.62)$, as well as criterion validity with the perceived Stress Scale $(r=0.472, p<0.01)$.

\subsubsection{Work Role Ambiguity}

This variable is defined as "reflecting certainty about duties, authority, allocation of time and relationships with others; the clarity or existence of guides, directives, policies; and the ability to predict sanctions as outcomes of behavior" [54]. The Ambiguity instrument measures work role ambiguity using six items measured on a 7-point Likert scale from 1 (strongly disagree) to 7 (strongly agree). A higher total score for role ambiguity means the respondent experiences more work role ambiguity. The reliability and validity of this scale have been tested everywhere [53]. As shown in the current study, the scale has good reliability (Chronbach's Alpha $=0.85)$. Also, the scale has a good criterion validity with perceived Stress Scale $(r=0.436, p<0.01)$.

\subsection{Demographic Variables}

First, age was measured in this study as a continuous variable. Second, gender was coded in this study to be male (1) and female (0). Third, the nationality of the health care workers was coded to be a dichotomous variable as Saudi (1) and non-Saudi (0). Fourth, marital status was a dichotomous variable as married (1) and not married (0). Fifth, education level was coded to be high school or less (0) and a university degree (1). Sixth, smoking in this study was coded as yes (1) and no (0). Seventh, type of job was recoded as medical and health job (1) and non-medical and health job (0). Eight, type of the health center was coded as regular health care center (1) and fever clinic (0). Ninth, regions were dummy coded into four dummy variables as following: Eastern (dummy 1), Western (dummy 2), Northern (dummy 3) and Southern (dummy 4). The Central region was used as a reference variable.

\subsection{Ethical Considerations}

This study was approved by the Central Institutional Review Board of the Ministry of Health in Saudi Arabia. The informed consent was on the first page of the electronic survey and included a description of the study, including the purpose and the names of the researchers. Anonymity was ensured since the names and I.P addresses were not collected. Also, to protect the confidentiality of the participants' data, the data were saved on the primary researcher's password-protected personal computer and no one had access to the data except the research team. Participants had to select "agree to participate" and "submit response" for their participation to be considered.

\subsection{Data Analysis}

Data were imported into the statistical software Statistical Package for the Social Sciences (SPSS, version 25) to analyze the study data. This study used a variety of statistical analysis procedures to analyze the data and the level of statistical significance was set to 0.05 for all used statistical tests. First, sociodemographic and occupational data were described. Second, Pearson correlation was used to examine the relationships between stress and all sociodemographic and occupational characteristics in addition to the workplace challenges. Third, linear regression analysis was used to assess the relationship between stress and the statistically significant factors in the correlation using two steps; step 1: control variables 
were entered and step 2: role conflict, role ambiguity, social support and self-esteem were entered. Fourth, independent sample t-tests were used to examine the differences between HCWs in regular and fever clinics in the levels of stress, role conflict and ambiguity, self-esteem and social support.

\section{Results}

The mean age (standard deviation) of participants was 38.9 (8.12) years; 908 (65.9\%) were aged 31 to 45 years old, $771(56.0 \%)$ were males, $1158(84.0 \%)$ were married and 1171 (85.0\%) were citizens. Regarding their job, 306 (22.2\%) were physicians, 432 (31.3\%) were nurses, 131 (9.5\%) were other HCWs, 509 (39.9\%) were administrative workers, 1101 $(79.9 \%)$ were working in a regular primary healthcare center and 277 (20.1\%) were working in fever clinics (Table 1).

Using Pearson correlation, stress correlated will all outcomes variables; positively with role conflict, role ambiguity and self-esteem and negatively with social support $(r=0.472,0.436,0.142$ and -0.220 ; respectively, $p$-values $<0.01$ in all correlations). Stress also correlated with other control variables; positively with a job and Eastern and Western regions $(r=0.096,0.083$ and 0.074$)$ and negatively with age, gender and center type ( $r=-0.307,-0.227$ and -0.069 ; respectively) (Table 2$)$. Several demographic variables were not significant, including (marital status, nationality, education level, smoking, Northern and western). These insignificant variables will not be included in the MRA because they violated the assumption of linearity.

In step 1 , stress was associated with age $(\beta=-0.234, p<0.01)$, followed by gender $(\beta=-0.157, p<0.01)$, nationality $(\beta=0.099, p<0.01)$ and center type $(\beta=-0.067, p<0.05)$. These factors explained $13 \%$ of stress. In step 2 , age $(\beta=-0.176, p<0.01)$ and gender $(\beta=-0.149, p<0.01)$ remained associated with stress. In addition, role conflict $(\beta=0.314$, $p<0.01)$, role ambiguity $(\beta=0.193, p<0.01)$, social support $(\beta=-0.099, p<0.01)$ and self-esteem $(\beta=0.088, p<0.01)$ were also associated with stress. Eventually, all of these factors together explained $35.4 \%$ of perceived stress, therefore, it could be concluded that workplace challenges in the form of role conflict, role ambiguity, social support and self-esteem contributed to $22.4 \%$ of stress (Table 3 ).

HCWs in fever clinics were shown by t-test to have higher levels of stress, role conflict and role ambiguity than their counterparts in the regular healthcare centers. The values of means (standard deviations) for fever clinics versus regular healthcare centers were as follows: stress: 18.70 (7.62) versus $17.33(7.54), p$-value= 0.007 , role conflict: $23.82(7.19)$ versus 22.85 (6.86), $p$-value $=0.038$ and role ambiguity: 17.56 (8.74) versus 16.19 (8.32), $p$-value $=0.016$, respectively (Table 4$)$. 
Table 1. Socio-demographic Characteristics of studied participants.

\begin{tabular}{|c|c|c|c|c|}
\hline Variable & No. (1378) & $\%$ & Mean & SD \\
\hline Age & & & 38.9 & 8.12 \\
\hline Less than 30 years & 197 & 14.3 & & \\
\hline 31 to 45 years & 908 & 65.9 & & \\
\hline 46 years or older & 273 & 19.8 & & \\
\hline \multicolumn{5}{|l|}{ Gender } \\
\hline Male & 771 & 56.0 & & \\
\hline Female & 607 & 44.0 & & \\
\hline \multicolumn{5}{|l|}{ Marital Status } \\
\hline Married/Living w/partner & 1158 & 84.0 & & \\
\hline Divorced/Separated & 54 & 3.9 & & \\
\hline Widowed & 11 & 0.8 & & \\
\hline Single & 155 & 11.2 & & \\
\hline \multicolumn{5}{|l|}{ Nationality } \\
\hline Citizen & 1171 & 85.0 & & \\
\hline Not Citizen & 207 & 15.0 & & \\
\hline \multicolumn{5}{|l|}{ Education Level } \\
\hline High school or less & 117 & 8.5 & & \\
\hline Two years of college & 652 & 47.3 & & \\
\hline Bachelor & 500 & 36.3 & & \\
\hline Graduate & 109 & 7.9 & & \\
\hline \multicolumn{5}{|l|}{ Type of health center } \\
\hline Regular PHC & 1101 & 79.9 & & \\
\hline fever clinic PHC & 277 & 20.1 & & \\
\hline \multicolumn{5}{|l|}{ Job } \\
\hline Physician & 306 & 22.2 & & \\
\hline Nurse & 432 & 31.3 & & \\
\hline Other health professionals & 131 & 9.5 & & \\
\hline Other & 509 & 39.9 & & \\
\hline \multicolumn{5}{|l|}{ Smoking } \\
\hline Yes & 271 & 19.7 & & \\
\hline No & 1107 & 80.3 & & \\
\hline \multicolumn{5}{|l|}{ Site of health center } \\
\hline Central & 235 & 23.6 & & \\
\hline Eastern & 128 & 9.3 & & \\
\hline Western & 337 & 24.4 & & \\
\hline Southern & 441 & 32.0 & & \\
\hline Northern & 147 & 10.7 & & \\
\hline
\end{tabular}


Table 2. Pearson correlation $[r]$ between stress and other work-related challenges.

\begin{tabular}{|c|c|c|c|c|c|c|c|c|c|c|c|c|c|c|c|c|c|}
\hline Variable & 1 & 2 & 3 & 4 & 5 & 6 & 7 & 8 & 9 & 10 & 11 & 12 & 13 & 14 & 14 & 16 & 17 \\
\hline Stress & 1 & & & & & & & & & & & & & & & & \\
\hline Age & $-\underset{* *}{0.307}$ & 1 & & & & & & & & & & & & & & & \\
\hline Gender & -0.227 & 0.220 ** & 1 & & & & & & & & & & & & & & \\
\hline $\begin{array}{c}\text { Marital } \\
\text { status }\end{array}$ & 0.033 & -0.026 & -0.023 & 1 & & & & & & & & & & & & & \\
\hline Nationality & $-0.047^{*}$ & $0.201^{* *}$ & $0.268^{* *}$ & -0.078 & 1 & & & & & & & & & & & & \\
\hline Education & 0.033 & -0.026 & -0.023 & -0.051 & $\underset{* *}{-0.456}$ & 1 & & & & & & & & & & & \\
\hline Center Type & $-0.069 *$ & 0.002 & 0.004 & -0.011 & 0.022 & -0.024 & 1 & & & & & & & & & & \\
\hline Job & $0.096^{* *}$ & $\underset{* *}{-0.137}$ & $\begin{array}{c}-0.279 \\
* *\end{array}$ & -0.038 & $\underset{* *}{-0.305}$ & $0.163^{* *}$ & -0.024 & 1 & & & & & & & & & \\
\hline Smoking & 0.001 & -0.019 & 0.332 ** & 0.031 & $0.147^{* *}$ & $\underset{* *}{-0.076}$ & -0.021 & $\underset{* *}{-0.166}$ & 1 & & & & & & & & \\
\hline Eastern & 0.083 * & -0.029 & $-\underset{* *}{0.128}$ & -0.026 & 0.044 & $0.090^{* *}$ & $\underset{* *}{-0.190}$ & $0.078^{* *}$ & -0.024 & 1 & & & & & & & \\
\hline Southern & 0.074 * & -0.028 & $-\underset{* *}{0.124}$ & 0.015 & $0.061 *$ & 0.017 & -0.061 * & 0.049 & -0.006 & $-\underset{* *}{-0.077}$ & 1 & & & & & & \\
\hline Northern & -0.014 & $-0.067^{*}$ & -0.008 & -0.037 & -0.040 & 0.029 & 0.052 & 0.035 & $-0.066^{*}$ & $\underset{* *}{-0.144}$ & $\underset{* *}{-0.115}$ & 1 & & & & & \\
\hline Western & -0.041 & $0.076^{* *}$ & $0.093^{* *}$ & 0.036 & 0.013 & $\underset{* *}{-0.074}$ & 0.042 & $-0.065^{*}$ & -0.008 & $\underset{* *}{-0.075}$ & $-0.060 *$ & -0.112 & 1 & & & & \\
\hline Conflict & $0.472 * *$ & $\underset{* *}{-0.173}$ & -0.025 & -0.054 * & 0.201 ** & -0.016 & $-0.056^{*}$ & 0.033 & 0.045 & 0.027 & 0.060 * & 0.030 & 0.030 & 1 & & & \\
\hline Ambiguity & $0.436^{* *}$ & -0.164 & -0.120 & -0.091 & $0.128^{* *}$ & -0.005 & -0.064 * & 0.101 ** & 0.011 & 0.065 * & 0.059 * & 0.006 & 0.039 & 0.508 ** & 1 & & \\
\hline $\begin{array}{c}\text { Social } \\
\text { Support }\end{array}$ & -0.220 & 0.029 & 0.034 & $0.057^{*}$ & $\underset{* *}{-0.104}$ & 0.042 & 0.049 & -0.029 & 0.011 & -0.013 & -0.038 & -0.010 & -0.012 & $\underset{* *}{-0.208}$ & $\underset{* *}{-0.260}$ & 1 & \\
\hline Self-Esteem & 0.142 ** & -0.049 & 0.004 & 0.001 & 0.026 & -0.059 * & -0.037 & 0.052 & 0.010 & -0.016 & -0.021 & 0.031 & $0.057^{*}$ & $0.098^{* *}$ & $0.235^{* *}$ & $\underset{* *}{-0.321}$ & 1 \\
\hline
\end{tabular}


Table 3. Linear regression analysis: work-related predictors of stress.

\begin{tabular}{|c|c|c|c|c|c|c|c|c|}
\hline \multirow[b]{2}{*}{ Variable } & \multicolumn{4}{|c|}{ Step 1} & \multicolumn{4}{|c|}{ Step 2} \\
\hline & $B$ & $S E$ & $\beta$ & $t$ & $B$ & $S E$ & $\beta$ & $t$ \\
\hline Age & $-0.179 * *$ & 0.027 & -0.234 & -6.713 & $-0.136^{* *}$ & 0.023 & -0.176 & -5.838 \\
\hline Gender & $-1.996^{* *}$ & 0.431 & -0.157 & -4.628 & $-1.891^{* *}$ & 0.374 & -0.149 & -5.059 \\
\hline Nationality & $1.686^{* *}$ & 0.613 & 0.099 & 2.748 & 0.183 & 0.537 & 0.011 & 0.340 \\
\hline Job & 0.711 & 0.474 & 0.053 & 1.502 & 0.172 & 0.409 & 0.013 & 0.421 \\
\hline Eastern & 0.630 & 0.723 & 0.029 & 0.872 & 0.390 & 0.625 & 0.018 & 0.624 \\
\hline Southern & 0.666 & 0.810 & 0.027 & 0.821 & 0.511 & 0.701 & 0.020 & 0.729 \\
\hline Center Type & $-1.031 *$ & 0.497 & -0.067 & -2.073 & -0.515 & 0.430 & -0.033 & -1.197 \\
\hline Conflict & & & & & $1.730^{* *}$ & 0.177 & 0.314 & 9.760 \\
\hline Ambiguity & & & & & $1.239 * *$ & 0.209 & 0.193 & 5.928 \\
\hline Social Support & & & & & $-0.052^{* *}$ & 0.015 & -0.099 & -3.382 \\
\hline Self-esteem & & & & & $1.466^{* *}$ & 0.480 & 0.088 & 3.053 \\
\hline Constant & $29.03 * *$ & 1.51 & & 19.24 & 16.946 & 2.211 & & 7.665 \\
\hline Adjusted $R^{2}$ & & 0.13 & & & & 0.354 & & \\
\hline$F$ & & $19.59 * *$ & & & & $44.23^{* *}$ & & \\
\hline
\end{tabular}

Step 1: control variables (age, gender, nationality, job, regions and type of the healthcare center) and step 2: further dependent variables (role conflict, role ambiguity, social support and self-esteem) ${ }^{*} p<0.05$ level (2-tailed). ${ }^{* *} p<0.01$ level (2-tailed).

Table 4. T-tests and Descriptive Statistics for Stress, Conflict, Ambiguity, Self-esteem and Social Support by Type of Health Center.

\begin{tabular}{cccccc}
\hline \multirow{2}{*}{ Variables } & \multicolumn{2}{c}{ Regular Center } & \multicolumn{2}{c}{ Fever Clinic } & \multirow{2}{*}{$p$-Value } \\
\cline { 2 - 5 } & Mean & SD & Mean & SD & \\
\hline Stress & 17.33 & 7.54 & 18.70 & 7.62 & 0.007 \\
Role conflict & 22.85 & 6.86 & 23.82 & 7.19 & 0.038 \\
Role ambiguity & 16.19 & 8.32 & 17.56 & 8.74 & 0.016 \\
Self-esteem & 18.17 & 4.04 & 18.54 & 3.92 & 0.167 \\
Social Support & 61.86 & 12.68 & 60.30 & 12.73 & 0.068 \\
\hline
\end{tabular}

\section{Discussion}

This study indicated that role conflict and ambiguity, self-esteem and social support were significant predictors for stress among HCWs in Saudi Arabia during the COVID-19 pandemic. Besides, HCWs who were working in fever clinics specialized to manage people with COVID-19 in Saudi Arabia had higher stress levels and role conflict and ambiguity than their counterparts who were working at regular primary healthcare centers.

The increased stress levels among HCWs in fever clinics who were on the frontlines during the COVID-19 pandemic came in line with previous national and international studies assessing stress among similar study populations. In a study conducted on 426 HCWs from Saudi Arabia and Egypt (48.4\% physicians, 24.2\% nurses and 27.4\% other HCWs) on the frontlines fighting COVID-19, more than half (55.9\%) of them had stress [55]. Another study conducted on 5062 HCWs (19.8\% physicians, $62.2 \%$ nurses and $18.0 \%$ technicians) treating patients with COVID-19 in China showed that $29.8 \%$ of participants had stress [56]. One study conducted on $346 \mathrm{HCW}$ from Spain $(90 \%$ of them were general practitioners) found that $63 \%$ of HCWs experienced stress during the COVID-19 pandemic [57].

In comparison with the general population or the HCWs managing diseases other than COVID-19, HCWs who inspect and treat patients with COVID-19 are more vulnerable to psychological deficits, including stress, for many reasons [58-60]. First, they are more likely to get infected with COVID-19 and consequently transmitting the infection to their family, friends and lovely ones. Second, they suffer a hefty workload that they have to 
work for more hours and attend extra shifts. Third, the worldwide shortage of personal protective equipment had a stressful impact on the mental status of HCWs. Fourth, in many cases, HCWs had to take meticulous precautions while they examine patients, which adds extra psychological burdens [55,61].

Furthermore, we could find that HCWs in fever clinics had higher levels of role conflict and role ambiguity than other HCWs in regular primary healthcare centers in Saudi Arabia. To the best of our knowledge, this is the first study to assess role conflict and ambiguity among HCWs from Saudi Arabia during the COVID-19 pandemic. The fever clinics were recently initiated in Saudi Arabia as a response measure to tackle the spread of COVID-19 across the country; therefore, it is not unexpected that HCWs in these new clinics do not have enough details on their job descriptions. They also might have incomplete knowledge of infection control precautions. Above all, the changing guidelines regarding COVID-19 precautionary and management protocols can be perplexing for HCWs managing COVID-19 patients. On the other hand, HCWs in other regular primary healthcare centers should have been occupying their places for years, so they are expected to have clear job descriptions, enough knowledge of the diseases they manage and strict protocols regulating their work. This discrepancy in job descriptions and knowledge of diseases could be the reason behind the differences in role conflict and role ambiguity between HCWs in fever clinics and regular primary healthcare centers in Saudi Arabia.

Moreover, our results demonstrated that role conflict and role ambiguity reported by HCWs in fever clinics were associated with their stress levels. This finding agrees with the results of previous studies conducted on workers from various disciplines. A self-report questionnaire administered to 66 health professionals in Italy showed that role ambiguity constituted a psychosocial deficit that influenced workers' wellbeing and led to emotional exhaustion [62]. In a cross-sectional study conducted on 2989 Japanese employees, work ambiguity was associated with psychological distress and even mediated the relationship between job insecurity and psychological distress [63].

Also, we could detect a negative correlation between social support and stress among the studied HCWs. In a previous study, Saudi HCWs who lacked emotional support from family and society during the COVID-19 pandemic showed higher levels of stress compared with their counterparts who received family and social support [55]. This finding highlights the need for providing social support to HCWs on the frontlines to alleviate their psychological stress.

Unexpectedly, we could notice a positive association between stress and self-esteem, which contradicted previous findings among HCWs [64,65]. While it is difficult to justify this finding, we could speculate that the high self-esteem among HCWs in our study could be partially explained by their experience in managing MERS-CoV pandemics. Thus, HCWs in Saudi Arabia who are stressed due to managing COVID-19 have good self-esteem due to the previous management of MERS-CoV. Still, more research is needed to confirm our findings. Still, the possibility of residual confounding cannot be excluded.

\section{Strength and Limitations}

This study poses many strengths that should be addressed, such as examining for the first time the status of role conflict and ambiguity among HCWs in Saudi Arabia during the COVID-19 and determining their association with stress, investigating a large sample, using a random sampling procedure to guarantee representativeness of the study population and allow extrapolation of results and assessing the exposures and outcomes using validated questionnaires. However, some limitations should be considered. First, the cross-sectional design of this study does not imply causality; therefore, prospective cohort studies are advised to confirm our findings. Second, some confounding variables that might have affected the results were not assessed, such as the availability of personal protective equipment and medical specialty. Third, due to the strict measures of social distancing, we had to access participants via e-mails; therefore, the possibility of non-response bias cannot be excluded since the sociodemographic and occupational characteristics of responders 
might have differed from non-responders. For example, HCWs with a busy schedule who probably have higher stress levels might have less time to check their e-mails and respond to the questionnaire [66].

\section{Conclusions}

This study revealed higher levels of stress and role conflict and ambiguity among HCWs in fever clinics during the COVID-19 pandemic than HCWs in regular primary healthcare centers in Saudi Arabia. Besides, role conflict and ambiguity, social support and self-esteem were found to be major determinants of stress among HCWs during the COVID-19 pandemics. Future programs and interventions should be considered to minimize role conflict and role ambiguity in fever clinics in Saudi Arabia to deliver the most efficient health services to patients with COVID-19.

Author Contributions: Conceptualization, K.A.-M. and F.A.; data curation, A.A. and F.A.; formal analysis, A.A., D.A. and M.A.; methodology, K.A.-M. and F.A.; project administration, K.A.-M.; supervision, K.A.-M. and F.A.; validation, F.A.; investigation, K.A.-M.; writing-original draft preparation, K.A.-M., M.A. and D.A.; writing-review and editing, A.A., D.A. and M.A. All authors have read and agreed to the published version of the manuscript.

Funding: This research received no external funding.

Institutional Review Board Statement: The study was conducted according to the guidelines of the Declaration of Helsinki and approved by the Central Institutional Review Board in Saudi Ministry of Health approval (approval number: 20-187M / and date of approval: 22/09/2020).

Informed Consent Statement: Informed consent was obtained from all subjects involved in the study.

Data Availability Statement: Data is available upon reasonable request by contacting the corresponding author.

Acknowledgments: The authors provide their appreciation to the scales authors which we used in the current study. Moreover, the authors thank the data collection team (Abdulrahman Alyahya, Khalid Alofi, Ali Aldoosary, Mansour Almalki, Ahmed Alrasheed, Emad Kushi, Saud Alotibi and, Raed Alnahedh). Additionally, the authors thank Saad Alyahya for his support in data analysis. Finally, the authors also thank leaders of primary health centers and healthcare workers who participated and assigned a part of their time to this study.

Conflicts of Interest: The authors declare no conflict of interest.

\section{References}

1. Zhu, N.; Zhang, D.; Wang, W.; Li, X.; Yang, B.; Song, J.; Zhao, X.; Huang, B.; Shi, W.; Lu, R.; et al. A Novel Coronavirus from Patients with Pneumonia in China, 2019. N. Engl. J. Med. 2020, 382, 727-733. [CrossRef] [PubMed]

2. Horesh, D.; Brown, A.D. Traumatic stress in the age of COVID-19: A call to close critical gaps and adapt to new realities. Psychol. Trauma 2020, 12, 331-335. [CrossRef]

3. World Health Organization. Coronavirus Disease 2019 (COVID-19) Situation Report-51. Available online: https: / /www.who. int/docs / default-source/ coronaviruse/situation-reports/20200311-sitrep-51-covid-19.pdf?sfvrsn=1ba62e57_10 (accessed on 27 August 2020).

4. World Health Organization. Coronavirus Disease 2019 (COVID-19) Weekly Operational Update Situation Report. Available online: https:/ / www.who.int/docs / default-source/coronaviruse/weekly-updates / wou-21082020.pdf?sfvrsn=e34ba8f3_2 (accessed on 27 November 2020).

5. Guanche, G.H. COVID-19. A challenge for healthcare professionals. Rev. Habanera Cienc. Med. 2020, 19, 1-4.

6. Talaee, N.; Varahram, M.; Jamaati, H.; Salimi, A.; Attarchi, M.; Dizaji, M.K.; Sadr, M.; Hassani, S.; Farzanegan, B.; Monjazebi, F.; et al. Stress and burnout in health care workers during COVID-19 pandemic: Validation of a questionnaire. J. Public Health 2020, 1-6. [CrossRef]

7. Yezli, S.; Khan, A. COVID-19 social distancing in the Kingdom of Saudi Arabia: Bold measures in the face of political, economic, social and religious challenges. Travel Med. Infect. Dis. 2020, 37, 101692. [CrossRef] [PubMed]

8. Johns Hopkins University and Medicine. Coronavirus Resource Center by Region (Saudi Arabia). Available online: https: / / coronavirus.jhu.edu/region/saudi-arabia (accessed on 8 November 2020).

9. Adly, H.M.; AlJahdali, I.A.; Garout, M.A.; Khafagy, A.A.; Saati, A.A.; Saleh, S.A. Correlation of COVID-19 Pandemic with Healthcare System Response and Prevention Measures in Saudi Arabia. Int. J. Environ. Res. Public Health 2020, $17,6666$. [CrossRef] 
10. Ministry of Health. The Kingdom of Saudi Arabia's: Experience in Health Preparedness and Response to COVID-19 Pandemic 2020. Available online: https://www.moh.gov.sa/en/Ministry/MediaCenter/Publications/Documents/COVID-19-NATIONAL. pdf (accessed on 3 December 2020).

11. Ortega-Galán, Á.M.; Ruiz-Fernández, M.D.; Lirola, M.-J.; Ramos-Pichardo, J.D.; Ibáñez-Masero, O.; Cabrera-Troya, J.; SalinasPérez, V.; Gómez-Beltrán, P.A.; Fernández-Martínez, E. Professional Quality of Life and Perceived Stress in Health Professionals before COVID-19 in Spain: Primary and Hospital Care. Healthcare 2020, 8, 484. [CrossRef] [PubMed]

12. Shechter, A.; Diaz, F.; Moise, N.; Anstey, D.E.; Ye, S.; Agarwal, S.; Birk, J.L.; Brodie, D.; Cannone, D.E.; Chang, B.; et al. Psychological distress, coping behaviors, and preferences for support among New York healthcare workers during the COVID-19 pandemic. Gen. Hosp. Psychiatry 2020, 66, 1-8. [CrossRef]

13. Cai, H.; Tu, B.; Ma, J.; Chen, L.; Fu, L.; Jiang, Y.; Zhuang, Q. Psychological Impact and Coping Strategies of Frontline Medical Staff in Hunan Between January and March 2020 During the Outbreak of Coronavirus Disease 2019 (COVID-19) in Hubei, China. Med. Sci. Monit. Int. Med. J. Exp. Clin. Res. 2020, 26, e924171.

14. Vizheh, M.; Qorbani, M.; Arzaghi, S.M.; Muhidin, S.; Javanmard, Z.; Esmaeili, M. The mental health of healthcare workers in the COVID-19 pandemic: A systematic review. J. Diabetes Metab. Disord. 2020, 19, 1967-1978. [CrossRef]

15. Ma, Y.; Rosenheck, R.; He, H. Psychological stress among health care professionals during the 2019 novel corona-virus disease Outbreak: Cases from online consulting customers. Intensive Crit. Care Nurs. 2020, 61, 102905. [CrossRef]

16. World Health Organization. MERS Situation Update January 2020. Available online: https://applications.emro.who.int/docs/ EMCSR254E.pdf?ua=1 (accessed on 3 December 2020).

17. Alsubaie, S.; Temsah, M.H.; Al-Eyadhy, A.A.; Gossady, I.; Hasan, G.M.; Al-Rabiaah, A.; Jamal, A.A.; Alhaboob, A.A.; Alsohime, F.; Somily, A.M. Middle East Respiratory Syndrome Coronavirus epidemic impact on healthcare workers' risk perceptions, work and personal lives. J. Infect. Dev. Ctries. 2019, 13, 920-926. [CrossRef] [PubMed]

18. Khalid, I.; Khalid, T.J.; Qabajah, M.R.; Barnard, A.G.; Qushmaq, I.A. Healthcare workers emotions, perceived stressors and coping strategies during a MERS-CoV outbreak. Clin. Med. Res. 2016, 14, 7-14. [CrossRef]

19. Park, J.S.; Lee, E.H.; Park, N.R.; Choi, Y.H. Mental health of nurses working at a government-designated hospital during a MERS-CoV outbreak: A cross-sectional study. Arch. Psychiatr. Nurs. 2018, 32, 2-6. [CrossRef]

20. Tunc, T.; Kutanis, R.O. Role conflict, role ambiguity, and burnout in nurses and physicians at a university hospital in Turkey. Nurs. Health Sci. 2009, 11, 410-416. [CrossRef] [PubMed]

21. Arafa, A.; Mohamed, A.; Saleh, L.; Senosy, S. Psychological Impacts of the COVID-19 Pandemic on the Public in Egypt. Community Ment. Heal. J. 2021, 57, 64-69. [CrossRef] [PubMed]

22. Johnson, A.R.; Jayappa, R.; James, M.; Kulnu, A.; Kovayil, R.; Joseph, B. Do Low Self-Esteem and High Stress Lead to Burnout Among Health-Care Workers? Evidence from a Tertiary Hospital in Bangalore, India. Saf. Health Work. 2020, 11, 347-352. [CrossRef]

23. Gray-Stanley, J.A.; Muramatsu, N.; Heller, T.; Hughes, S.; Johnson, T.P.; Ramirez-Valles, J. Work stress and depression among direct support professionals: The role of work support and locus of control. J. Intellect. Disabil. Res. 2010, 54, 749-761. [CrossRef]

24. Tae, Y.S.; Heitkemper, M.; Kim, M.Y. A path analysis: A model of depression in Korean women with breast cancer-mediating effects of self-esteem and hope. Oncol. Nurs. Forum 2012, 39-57. [CrossRef]

25. Pearce, J.L. Bringing Some Clarity to Role Ambiguity Research. Acad. Manag. Rev. 1981, 6, 665. [CrossRef]

26. Beard, F.K. Client role ambiguity and satisfaction in client-ad agency relationships. J. Advert. Res. 1999, 39, 69-78.

27. Thoits, P.A. Stress and Health: Major Findings and Policy Implications. J. Health Soc. Behav. 2010, 51, S41-S53. [CrossRef] [PubMed]

28. Adamczyk, K.; Segrin, C. Perceived Social Support and Mental Health among Single vs. Partnered Polish Young Adults. Curr. Psychol. 2015, 34, 82-96. [CrossRef]

29. Lee, J.-S.; Koeske, G.F.; Sales, E. Social support buffering of acculturative stress: A study of mental health symptoms among Korean international students. Int. J. Intercult. Relat. 2004, 28, 399-414. [CrossRef]

30. Alyahya, S.A. Psychological Stress among Informal Caregivers. Ph.D. Thesis, The Catholic University of America, Washington, DC, USA, 2020.

31. Lazarus, R.S.; Folkman, S. Cognitive Theories of Stress and the Issue of Circularity. In Dynamics of Stress; Springer International Publishing: Boston, MA, USA, 1986; pp. 63-80.

32. Lazarus, R.S. Theory-Based Stress Measurement. Psychol. Inq. 1990, 1, 3-13. [CrossRef]

33. Lambert, V.A.; Lambert, C.E. Literature review of role stress/strain on nurses: An international perspective. Nurs. Health Sci. 2001, 3, 161-172. [CrossRef]

34. Khamisa, N.; Peltzer, K.; Oldenburg, B. Burnout in Relation to Specific Contributing Factors and Health Outcomes among Nurses: A Systematic Review. Int. J. Environ. Res. Public Health 2013, 10, 2214-2240. [CrossRef]

35. Montgomery, A.; Spânu, F. Băban, A.; Panagopoulou, E. Job demands, burnout and engagement among nurses: A multi-level analysis of ORCAB data investigating the moderating effect of teamwork. Burn. Res. 2015, 2, 71-79. [CrossRef]

36. García-Herrero, S.; Lopez-Garcia, J.R.; Herrera, S.; Fontaneda, I.; Báscones, S.M.; Mariscal, M.A. The Influence of Recognition and Social Support on European Health Professionals' Occupational Stress: A Demands-Control-Social Support-Recognition Bayesian Network Model. BioMed Res. Int. 2017, 2017, 1-14. [CrossRef] [PubMed] 
37. Cohen, S. Perceived stress in a probability sample of the United States. The Claremont Symposium on Applied Social Psychology. In The Social Psychology of Health; Spacapan, S., Oskamp, S., Eds.; Sage Publications, Inc.: Newbury Park, CA, USA, 1988 ; pp. 31-67.

38. Cohen, S.; Kamarck, T.; Mermelstein, R. Perceived stress scale. Meas. Stress Guide Health Soc. Sci. 1994, 10, 1-2.

39. Almajwal, A.M. Stress, shift duty and eating behavior among nurses in Riyadh, Saudi Arabia. FASEB J. 2016, $30,1 b 324$.

40. Alharbi, H.; Alshehry, A. Perceived stress and coping strategies among ICU nurses in government tertiary hospitals in Saudi Arabia: A cross-sectional study. Ann. Saudi Med. 2019, 39, 48-55. [CrossRef] [PubMed]

41. Siddiqui, A.F.; Al Zaalah, M.A.; Alqahtani, A.A.; Alqahtani, M.A.S. Perceived stress and its associated sociodemographic factors among physicians working in Aseer region of Saudi Arabia. J. Liaquat. Uni. Med. Health Sci. 2017, 16, 10-18.

42. Chaaya, M.; Osman, H.; Naassan, G.; Mahfoud, Z. Validation of the Arabic version of the Cohen perceived stress scale (PSS-10) among pregnant and postpartum women. BMC Psychiatry 2010, 10, 111. [CrossRef]

43. Rosenberg, M.; Schooler, C.; Schoenbach, C. Self-Esteem and Adolescent Problems: Modeling Reciprocal Effects. Am. Sociol. Rev. 1989, 54, 1004. [CrossRef]

44. Silber, E.; Tippett, J.S. Self-Esteem: Clinical Assessment and Measurement Validation. Psychol. Rep. 1965, 16, 1017-1071. [CrossRef]

45. Gray-Little, B.; Williams, V.S.L.; Hancock, T.D. An Item Response Theory Analysis of the Rosenberg Self-Esteem Scale. Pers. Soc. Psychol. Bull. 1997, 23, 443-451. [CrossRef]

46. Alsaqri, S.H.; Albagawi, B.S.; Aldalaykeh, M.K.; Alkuwaisi, M.J. Prediction of Depression among Undergraduate Nursing Students in North-Western Saudi Arabia: A Quantitative Cross-Sectional Study. Int. J. Adv. Appl. Sci. Taiwan 2019, 6, $72-78$.

47. Lin, N. Conceptualizing Social Support. In Social Support, Life Events and Depression; Lin, N., Dean, A., Ensel, W., Eds.; Elsevier: New York, NY, USA, 1986; pp. 17-30.

48. Zalaquett, C.P.; Wood, R.J. Evaluating Stress: A Book of Resources; The Scarecrow Press: London, UK, 1998 ; pp. $185-197$.

49. Zimet, G.D.; Dahlem, N.W.; Zimet, S.G.; Farley, G.K. The Multidimensional Scale of Perceived Social Support. J. Pers. Assess. 1988, 52, 30-41. [CrossRef]

50. Rizwan, M.; Aftab, S. Psychometric properties of the multidimensional scale of perceived social support in Pakistani young adults. Pak. J. Psychol. 2009, 40, 51-65.

51. Aroian, K.; Templin, T.N.; Ramaswamy, V. Adaptation and Psychometric Evaluation of the Multidimensional Scale of Perceived Social Support for Arab Immigrant Women. Health Care Women Int. 2010, 31, 153-169. [CrossRef]

52. Kahn, R.L.; Wolfe, D.M.; Quinn, R.P.; Snoek, J.D.; Rosenthal, R.A. Organizational Stress: Studies in Role Conflict and Ambiguity; Wiley: New York, NY, USA, 1964.

53. Bowling, N.A.; Khazon, S.; Alarcon, G.M.; Blackmore, C.E.; Bragg, C.B.; Hoepf, M.R.; Barelka, A.; Kennedy, K.; Wang, Q.; Li, H. Building better measures of role ambiguity and role conflict: The validation of new role stressor scales. Work. Stress 2017, 31, 1-23. [CrossRef]

54. Rizzo, J.R.; House, R.J.; Lirtzman, S.I. Role Conflict and Ambiguity in Complex Organizations. Adm. Sci. Q. 1970, 15, 150. [CrossRef]

55. Arafa, A.; Mohammed, Z.; Mahmoud, O.; Elshazley, M.; Ewis, A. Depressed, anxious, and stressed: What have healthcare workers on the frontlines in Egypt and Saudi Arabia experienced during the COVID-19 pandemic? J. Affect. Disord. 2021, 278, 365-371. [CrossRef] [PubMed]

56. Zhu, Z.; Xu, S.; Wang, H.; Liu, Z.; Wu, J.; Li, G.; Zhu, S. COVID-19 in Wuhan: Sociodemographic characteristics and hospital support measures associated with the immediate psychological impact on healthcare workers. EClinicalMedicine 2020, 24, 100443. [CrossRef]

57. Odriozola-González, P.; Planchuelo-Gómez, Á.; Irurtia, M.J.; de Luis-García, R. Psychological symptoms of the out-break of the COVID-19 confinement in Spain. J. Health Psychol. 2020. [CrossRef]

58. Lai, J.; Ma, S.; Wang, Y.; Cai, Z.; Hu, J.; Wei, N.; Wu, J.; Du, H.; Chen, T.; Li, R.; et al. Factors Associated with Mental Health Outcomes among Health Care Workers Exposed to Coronavirus Disease 2019. JAMA Netw. Open 2020, 3, e203976. [CrossRef]

59. Roy, D.; Tripathy, S.; Kar, S.K.; Sharma, N.; Verma, S.K.; Kaushal, V. Study of knowledge, attitude, anxiety \& perceived mental healthcare need in Indian population during COVID-19 pandemic. Asian J. Psychiatry 2020, 51, 102083.

60. De Pablo, G.S.; Vaquerizo-Serrano, J.; Catalan, A.; Arango, C.; Moreno, C.; Ferre, F.; Shin, J.I.; Sullivan, S.; Brondino, N.; Solmi, M.; et al. Impact of coronavirus syndromes on physical and mental health of health care workers: Systematic review and meta-analysis. J. Affect. Disord. 2020, 275, 48-57. [CrossRef] [PubMed]

61. Joob, B.; Wiwanitkit, V. Traumatization in medical staff helping with COVID-19 control. Brain Behav. Immun. 2020, 87, 10. [CrossRef] [PubMed]

62. Chiara, P.; Luca, C.; Annalisa, P.; Chiara, R.; Panari, C.; Caricati, L.; Pelosi, A.; Rossi, C. Emotional exhaustion among healthcare professionals: The effects of role ambiguity, work engagement and professional commitment. Acta Bio Med. Atenei Parm. 2019, 90, 60-67.

63. Inoue, A.; Kawakami, N.; Eguchi, H.; Tsutsumi, A. Interaction effect of job insecurity and role ambiguity on psychological distress in Japanese employees: A cross-sectional study. Int. Arch. Occup. Environ. Health 2018, 91, 391-402. [CrossRef] [PubMed]

64. Leão, E.R.; Fabbro, D.R.D.; De Oliveira, R.B.; Dos Santos, I.R.; Victor, E.D.S.; Aquarone, R.L.; Andrade, C.B.; Ribeiro, V.F.; De Oliveira, R.C.; Friedlander, R.; et al. Stress, self-esteem and well-being among female health professionals: A randomized clinical trial on the impact of a self-care intervention mediated by the senses. PLoS ONE 2017, 12, e0172455. [CrossRef] [PubMed] 
65. Molero Jurado, M.D.; Pérez-Fuentes, M.D.; Gázquez Linares, J.J.; Barragán Martín, A.B. Burnout in health professionals according to their self-esteem, social support and empathy profile. Front. Psychol. 2018, 9, 424. [CrossRef] [PubMed]

66. Arafa, A.E.; Anzengruber, F.; Mostafa, A.M.; Navarini, A.A. Perspectives of online surveys in dermatology. J. Eur. Acad. Dermatol. Venereol. 2018, 33, 511-520. [CrossRef] [PubMed] 